\title{
Beta Carotene Measurement
}

National Cancer Institute

\section{Source}

National Cancer Institute. Beta Carotene Measurement. NCI Thesaurus. Code C100472.

The determination of the amount of beta-carotene present in a sample. 